\title{
Front Matter: Volume 7989
}

, "Front Matter: Volume 7989," Proc. SPIE 7989, Network Architectures, Management, and Applications VIII, 798901 (19 January 2011); doi: 10.1117/12.890179

SPIE Event: Asia Communications and Photonics Conference and Exhibition, 2010, Shanghai, Shanghai, China 


\title{
PROCEEDINGS OF SPIE
}

\section{Network Architectures, Management, and Applications VIII}

\author{
Lena Wosinska \\ Soichiro Araki \\ Yaohui Jin \\ Jing Wu \\ Editors \\ 8-12 December 2010 \\ Shanghai, China \\ Cosponsored by \\ IEEE Photonics Society • Optical Society of America • SPIE • Chinese Optical Society \\ China Institute of Communications \\ Local Organizing Committee \\ Fudan University - Pudong Optoelectronics Industry Association of Shanghai \\ Shanghai Jiao Tong University • Shanghai Institute of Optics and Fine Mechanics \\ Alcatel-Lucent Shanghai Bell \\ Best Student Paper Sponsor \\ Thorlabs, Inc. \\ Published by \\ SPIE • Optical Society of America • IEEE Photonics Society
}

Volume 7989

Proceedings of SPIE, 0277-786X, v. 7989 
The papers included in this volume were part of the technical conference cited on the cover and title page. Papers were selected and subject to review by the editors and conference program committee. Some conference presentations may not be available for publication. The papers published in these proceedings reflect the work and thoughts of the authors and are published herein as submitted. The publisher is not responsible for the validity of the information or for any outcomes resulting from reliance thereon.

Please use the following format to cite material from this book:

Author(s), "Title of Paper," in Network Architectures, Management, and Applications VIII, edited by Lena Wosinska, Soichiro, Araki, Yaohui Jin, Jing Wu, Proceedings of SPIE-OSA-IEEE Asia Communications and Photonics, SPIE Vol. 7989 (SPIE, Bellingham, WA, 2011) Article CID Number.

ISSN 0277-786X

ISBN 9780819485571

Published by

SPIE

P.O. Box 10, Bellingham, Washington 98227-0010 USA

Telephone +1 3606763290 (Pacific Time) · Fax +1 3606471445

SPIE.org

\section{Optical Society of America}

2010 Massachusetts Ave., N.W., Washington, D.C., 20036 USA

Telephone +1 2022238130 (Eastern Time) · Fax +1 2022231096

OSA.org

\section{IEEE Photonics Society}

445 Hoes Lane, Piscataway, New Jersey, 08855 USA

Telephone +1 7325628434 (Eastern Time) · Fax +1 7325628434

IEEE.org

Copyright (C) 201 1, Society of Photo-Optical Instrumentation Engineers, Optical Society of America, and IEEE Photonics Society.

Copying of material in this book for internal or personal use, or for the internal or personal use of specific clients, beyond the fair use provisions granted by the U.S. Copyright Law is authorized by SPIE subject to payment of copying fees. The Transactional Reporting Service base fee for this volume is $\$ 18.00$ per article (or portion thereof), which should be paid directly to the Copyright Clearance Center (CCC), 222 Rosewood Drive, Danvers, MA 01923. Payment may also be made electronically through CCC Online at copyright.com. Other copying for republication, resale, advertising or promotion, or any form of systematic or multiple reproduction of any material in this book is prohibited except with permission in writing from the publisher. The CCC fee code is 0277-786X/11/\$18.00.

Printed in the United States of America.

Publication of record for individual papers is online in the SPIE Digital Library.

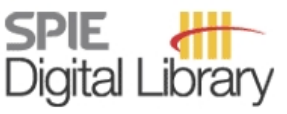

SPIEDigitalLibrary.org

Paper Numbering: Proceedings of SPIE follow an e-First publication model, with papers published first online and then in print and on CD-ROM. Papers are published as they are submitted and meet publication criteria. A unique, consistent, permanent citation identifier (CID) number is assigned to each article at the time of the first publication. Utilization of CIDs allows articles to be fully citable as soon they are published online, and connects the same identifier to all online, print, and electronic versions of the publication. SPIE uses a six-digit CID article numbering system in which:

- The first four digits correspond to the SPIE volume number.

- The last two digits indicate publication order within the volume using a Base 36 numbering system employing both numerals and letters. These two-number sets start with 00, 01, 02, 03, 04, 05, 06, 07, 08, $09,0 A, O B \ldots$. OZ, followed by 10-1Z, 20-2Z, etc.

The CID number appears on each page of the manuscript. The complete citation is used on the first page, and an abbreviated version on subsequent pages. Numbers in the index correspond to the last two digits of the six-digit CID number. 


\section{Contents}

ix Symposium Committees

xi Conference Committee

\section{NETWORK PLANNING}

798902 Hybrid hierarchical optical path network design algorithm with 2-stage ILP optimization [7989-27]

H.-C. Le, H. Hasegawa, K. Sato, Nagoya Univ. (Japan)

798903 A hierarchical path computation element (PCE)-based routing algorithm in multi-domain WDM networks [7989-36]

S. Shang, X. Zheng, H. Zhang, N. Hua, H. Zhang, Tsinghua Univ. (China)

798904 Impact of configuration time on lightpath establishment in transparent WDM networks [7989-31]

J. Li, J. Zhang, Y. Zhao, W. Gu, Y. Ji, Beijing Univ. of Posts and Telecommunications (China)

798905 A wavelength-rotation-based concurrent collision avoidance scheme in optical WDM networks [7989-04]

N. Hua, X. Zheng, H. Zhang, B. Zhou, Tsinghua Univ. (China)

\section{LABEL SWITCHING AND GMPLS}

798906 Design of optical flow switched network with generalized survivable network [7989-39]

K. S. Ho, K. W. Cheung, The Chinese Univ. of Hong Kong (Hong Kong, China)

798907 A PCE/GMPLS-based collision-avoiding wavelength assignment scheme for WSONs [7989-37]

J. Xie, M. Zhang, L. Zhang, Y. Ji, J. Zhang, P. Ye, Beijing Univ. of Posts and

Telecommunications (China)

\section{NETWORK PROTECTION}

798908 Availability analysis of permanent dedicated path protection in WDM mesh networks [7989-26]

Y. Li, W. Ni, Y. Li, X. Zheng, Tsinghua Univ. (China)

798909 Differentiated protection services with failure probability guarantee for workflow-based applications [7989-54]

Y. Zhong, W. Guo, Y. Jin, W. Sun, W. Hu, Shanghai Jiao Tong Univ. (China) 
7989 OA Attack-aware planning and optimization in transparent optical networks (Invited Paper) [7989-61]

N. Skorin-Kapov, Univ. of Zagreb (Croatia)

7989 OB Optical receiver sensitivity analysis for electronic code division multiple access over passive optical network [7989-20]

Y. Han, S. Liang, L. Wang, X. Chen, Beijing Univ. of Posts and Telecommunications (China)

\section{FIBER TO THE HOME}

7989 OC Migration towards fibre to the home: key cost factors [7989-33]

L. W. Zhou, Detecon International GmbH (Germany) and Technische Univ. München (Germany); C. Mas Machuca, Technische Univ. München (Germany); R. Zhao, K. Grunert, Detecon International GmbH (Germany)

\section{PASSIVE OPTICAL ACCESS AND CORE NETWORKS}

7989 OD Using wavelength-tunable self-seeding Fabry-Perot laser for upstream transmission in hybrid WDM/TDM PON [7989-01]

M. Zhu, S. Xiao, W. Guo, M. Bi, Z. Zhou, Y. Jin, W. Hu, Shanghai Jiao Tong Univ. (China)

7989 OE Effects of the channel switch latency in hybrid WDM/TDM PON [7989-10]

Z. Zhou, S. Xiao, M. Zhu, M. Bi, Y. Xiang, C. Yang, J. Wei, Shanghai Jiao Tong Univ. (China)

\section{NETWORK REQUIREMENTS AND EXPERIMENTS}

7989 OF Field demonstration of dynamic circuit provisioning by web services interface proxy for lambda and ethernet based administrative domains [7989-34]

T. Miyamoto, KDDI R\&D Labs. Inc. (Japan); J. Tanaka, KDDI Corp. (Japan); H. Otsuki, National Institute of Information and Communications Technology (Japan); T. Kudoh, R. Takano, National Institute of Advanced Industrial Science and Technology (Japan); M. Hayashi, I. Morita, K. Nishimura, KDDI R\&D Labs. Inc. (Japan); S. Shimojo, National Institute of Information and Communications Technology (Japan)

7989 OG GMPLS controlled multi-layer ethernet [7989-44]

V. Nordell, A. Gavler, P. Sköldström, Acreo AB (Sweden)

\section{MULTI-LAYER OPTICAL NETWORKS}

$7989 \mathrm{OH} \quad$ Research on unified control plane design for multi-layer optical networks (Invited Paper) [7989-42]

J. Zhang, Y. Zhao, W. GU, Y. Ji, Beijing Univ. of Posts and Telecommunications (China) 
7989 ol A dynamic path control method applying traffic-prediction-based route pre-prioritization [7989-28]

H. Ohno, H. Hasegawa, K. Sato, Nagoya Univ. (Japan)

7989 0J A demonstration of session-based resource reservation interface for inter-NGN QoS control [7989-35]

N. Matsumoto, M. Hayashi, K. Nishimura, H. Tanaka, KDDI R\&D Labs. Inc. (Japan)

\section{VIRTUAL NETWORK}

7989 OK Efficient algorithms for survivable virtual network embedding [7989-05]

G. Sun, H. YU, L. Li, Univ. of Electronic Science and Technology of China (China); V. Anand, The College at Brockport, SUNY (United States); H. Di, X. Gao, Univ. of Electronic Science and Technology of China (China)

7989 OL Cost efficient virtual infrastructure mapping using subgraph isomorphism [7989-18] H. Di, L. Li, Univ. of Electronic Science and Technology of China (China); V. Anand, The College at Brockport, SUNY (United States); H. Yu, G. Sun, Univ. of Electronic Science and Technology of China (China)

\section{ENERGY EFFICIENT DESIGN}

7989 0M Design considerations toward low-power-consuming optical network elements (Invited Paper) [7989-51]

S. Aleksić, Vienna Univ. of Technology (Austria)

7989 ON Energy efficient design and routing for IP over dynamic optical networks [7989-23]

L. Wang, R. LU, X. Zheng, H. Zhang, Tsinghua Univ. (China)

798900 Energy efficient design based on the coordination of management and control in a multi-domain WSON [7989-25]

L. Lv, S. Huang, Beijing Univ. of Posts and Telecommunications (China); C. Phillips, Univ. of London (United Kingdom); H. Huang, J. Zhang, Beijing Univ. of Posts and

Telecommunications (China); X. Zhang, Univ. of London (United Kingdom); B. Guo, Y. Zhang, Beijing Univ. of Posts and Telecommunications (China)

\section{MEDIA ACCESS CONTROL}

7989 OP Cost-effective IP core network operations based on multi-layer network planning (Invited Paper) [7989-59]

S. Ishida, I. Nishioka, S. Araki, NEC Corp. (Japan)

$7989 \mathrm{OQ}$ A hybrid MAC protocol design for energy-efficient very-high-throughput millimeter wave, wireless sensor communication networks [7989-15]

W. Jian, Beijing Univ. of Post and Telecommunication (China) and Georgia Institute of Technology (United States); C. I. Estevez, A. Chowdhury, Z. Jia, Georgia Institute of Technology (United States); J. Wang, J. Yu, State Key Lab. of Optical Communication Technologies Networks (China); G.-K. Chang, Georgia Institute of Technology (United States) 
7989 OR DPSK modulated video service overlaid wavelength division multiplexed OFDM-PON [7989-14]

X. Xin, L. Zhang, B. Liu, Y. Wang, Q. Zhang, Beijing Univ. of Posts and Telecommunications (China)

\section{PHYSICAL IMPAIRMENTS IN OPTICAL NETWORKS}

7989 OS Is it viable to encompass physical impairment within GMPLS control plane of optical networks? (Invited Paper) [7989-45]

P. Castoldi, Scuola Superiore Sant'Anna (Italy)

7989 OT A novel RoF architecture with optical single sideband $\mathrm{mm}$-wave signal generation using frequency doubling and wavelength reuse for uplink connection [7989-09]

H. Wen, J. Li, Q. Jing, L. Xu, C. Li, Hunan Univ. of Technology (China)

\section{FIBER ACCESS NETWORKS}

7989 OU Fiber-wireless (FiWi) access networks for a green video-dominated future internet (Invited Paper) [7989-52] M. Maier, Optical Zeitgeist Lab., INRS (Canada)

7989 OV Enhancement of fairness among broadband users with heterogeneous access network resources management [7989-16]

N. Matsumoto, M. Hayashi, K. Nishimura, H. Tanaka, KDDI R\&D Labs Inc. (Japan)

7989 OW A comparative model and techno-economic analysis of next generation AON ethernet and TDM PON [7989-60]

K. Wang, C. P. Larsen, A. Gavler, Acreo AB (Sweden); B. Lannoo, Ghent Univ. (Belgium);

D. Chiaroni, Alcatel-Lucent Bell Labs (France); M. Popov, Acreo AB (Sweden)

\section{POSTER SESSION}

7989 OX The impact of waveband size on the number of ports of cross-connect in waveband switching networks [7989-57]

R. Karube, K. Takano, T. Ito, K. Nakagawa, Yamagata Univ. (Japan)

7989 OY DREAMCSAPE: a dual-routing-engine-enabled multi-domain multi-layer optical network platform [7989-81]

M. Zhang, Y. Zhao, Y. Ji, J. Zhang, Y. Wang, J. Xie, H. Ding, K. Wu, Beijing Univ. of Posts and Telecommunications (China)

$7989 \mathrm{OZ}$ A novel scheme for frequency and time information transfer over OTN [7989-55]

C. Fang, P. Yang, X. Chen, Beijing Univ. of Posts and Telecommunications (China)

798910 A kind of QoS scheme in EPON-WiMAX hybrid access network [7989-50]

K. He, Z. Zhang, N. Wang, X. Chen, Beijing Univ. of Posts and Telecommunications (China)

798911 Dynamic connection provisioning in mixed-line-rate optical networks [7989-11]

Y. Chen, Tsinghua Univ. (China) and State Univ. of New York at Buffalo (United States);

N. Hua, X. Zheng, H. Zhang, Tsinghua Univ. (China) 
798912 Efficient modeling of location decision for PCEs in multi-domain optical networks [7989-58] W. Xie, Beijing Univ. of Posts and Telecommunications (China); J. Song, Huaxin Consulting Co., Ltd (China); L. Lu, Beijing Univ. of Posts and Telecommunications (China); Y. Xia, Huaxin Consulting Co., Ltd (China); D. Wang, ZTE Corp. (China); S. Huang, W. Gu, Beijing Univ. of Posts and Telecommunications (China)

798913 An enhanced PCE-based scheme for end-to-end multi-domain diverse path computation [7989-12]

Y. Wang, Y. Peng, X. Chen, K. Long, Univ. of Electronic Science and Technology of China (China)

$798914 \quad$ MAC protocol with dynamic priority adjustment for light trail networks [7989-47]

S. Li, Z. Le, M. Fu, Z. Zhu, Zhejiang Univ. of Technology (China); W. Fang, Changchun Institute of Optics, Fine Mechanics and Physics (China)

798915 The implementation of a novel P2P service redirection mechanism in passive optical network [7989-13]

X. Jiang, X. Chen, D. Ma, N. Wang, Beijing Univ. of Posts and Telecommunications (China)

798916 Data vortex photonic network with non-crossing control links layout [7989-46]

Q. Yang, Harvey Mudd College (United States)

798917 Incremental network design with topology augmentation on backup path provisioning in WDM mesh networks [7989-22]

Q. Li, W. Ni, Y. Li, H. Zhang, X. Zheng, Tsinghua Univ. (China)

\section{POST-DEADLINE SESSION}

798918 Experimental demonstration of DREAMSCAPE with more than 1000 GMPLS-based control nodes [7989-19]

Y. Zhao, J. Zhang, M. Zhang, Y. Ji, W. Gu, Beijing Univ. of Posts and Telecommunications (China)

Author Index 
Downloaded From: https://www.spiedigitallibrary.org/conference-proceedings-of-spie on 26 Apr 2023

Terms of Use: https://www.spiedigitallibrary.org/terms-of-use 


\title{
Symposium Committees
}

\author{
General Chairs
}

Weishing Hu, Shanghai Jiao Tong University (China)

Ming-Jun Li, Corning, Inc. (United States)

Dennis L. Matthews, University of California, Davis (United States)

Technical Program Chairs

Dominique Chiaroni, Alcatel-Lucent (France)

Jian-Jun He, Zhejiang University (China)

Ken-ichi Kitayama, Osaka University (Japan)

Xingde Li, John Hopkins University (United States)

Local Organizing Committee

Nan Chi (Chair), Fudan University (China)

Chansai Cheng, Pudong Optoelectronics Industry Association of

Shanghai (China)

Meiyu Cao, Pudong Optoelectronics Industry Association of Shanghai (China)

Yaohui Jin, Shanghai Jiao Tong University (China)

Ronghui Qu, Shanghai Institute of Optics and Fine Mechanics (China)

Feng Huang, Alcatel-Lucent Shanghai Bell (China)

Organizing Committee

Lirong Zheng, Fudan University (China)

Liangyao Chen, Fudan University (China)

Yiwei Shi, Fudan University (China)

Bo Hu, Fudan University (China)

Rongjun Zhang, Fudan University (China)

Zhengcai Bian, Fudan University (China)

Jianjun Yin, Fudan University (China)

Xinyue Guo, Fudan University (China)

Xiaolu Wan, Fudan University (China)

General Secretariat

Yufeng Shao, Fudan University (China) 
Steering Committee Chairs

Kwok-Wai Cheung, Chinese University of Hong Kong (Hong Kong, China)

Thomas Koch, Lehigh University (United States)

John Zyskind, Mintera Corporation (United States)

Steering Committee Members

Connie Chang-Hasnain, University of California at Berkeley (United States)

Chongcheng Fan, Tsinghua University (China)

Sailing He, Zheijang University (China)

Peter Kaiser, Telcordia Technologies (retired) (United States)

Thomas Koch, Lehigh University (United States)

Ming-Jun Li, Corning, Inc. (United States)

Tingye Li, AT\&T Laboratories (retired) (United States)

Mao Qian, WRI-Fiberhome (China)

Xiaomin Ren, Beijing University of Posts and Telecommunications (China)

Bingkun Zhou, Tsinghua University (China) 


\title{
Conference Committee
}

\author{
Conference Chair
}

Lena Wosinska, Royal Institute of Technology (Sweden)

Conference Cochairs

Soichiro Araki, NEC Corporation (Japan)

Yaohui Jin, Shanghai Jiao Tong University (China)

Jing Wu, Communications Research Center Canada (Canada)

Program Committee

Dirk Breuer, Deutsche Telekom AG (Germany)

Xiaojun Cao, Georgia State University (United States)

Stefan Dahlfort, Ericsson (Sweden)

Wei Guo, Shanghai Jiao Tong University (China)

Hiroshi Hasegawa, Nagoya University (Japan)

Hideaki Imaizumi, University of Tokyo Research Center for Advanced Science and Technology (Japan)

Andrzej Jajszczyk, AGH University of Science and Technology (Poland)

Masahiko Jinno, NTT Network Innovation Laboratories (Japan)

Jason Jue, University of Texas at Dallas (United States)

Susumu Kinoshita, Fujitsu Laboratories Ltd. (Japan)

Zhengbin Li, Peking University (China)

Carmen Mas Machuca, Technische Universität München (Germany)

Takaya Miyazawa, National Institute of Information and

Communications Technology (Japan)

Paolo Monti, Royal Institute of Technology (Sweden)

Satoru Okamoto, Keio University (Japan)

Carla Raffaelli, Università di Bologna (Italy)

George Rouskas, North Carolina State University (United States)

Shoichiro Seno, Mitsubishi Electric Corporation Japan

Chengbin Shen, Shanghai Telecom Technology Research Institute of China Telecom (China)

Gangxiang Shen, Ciena Corporation (United States)

Nina Skorin-Kapov, University of Zagreb (Croatia)

Arun Somani, lowa State University (United States)

Takehiro Tsuritani, KDDI R\&D Laboratories (Japan)

Anna Tzanakaki, Athens Information Technology Center (Greece)

Jianping Wang, City University of Hong Kong (Hong Kong, China)

Hongfang Yu, University of Electronic Science and Technology of China (China)

Guoying Zhang, China Academy of Telecommunication Research of MIIT (China) 
Jie Zhang, Beijing University of Posts and Telecommunications (China)

Xiaoping Zheng, Tsinghua University (China)

Luying Zhou, Institute for Infocomm Research (Singapore)

\section{Session Chairs}

Network Planning

Nina Skorin-Kapov, University of Zagreb (Croatia)

Switching and GMPLS

Ken-ichi Sato, Nagoya University (Japan)

Network Protection

Carmen Mas Machuca, Technische Universität München (Germany)

Optical Networks

Jing Wu, Communications Research Center (Canada)

Fiber to the Home

Lena Wosinska, Royal Institute of Technology (Sweden)

Passive Optical Access and Core Networks

Gangxiang Shen, Soochow University (China)

Network Requirements and Experiments

Piero Castoldi, Scuola Superiore di Studi Universitari e di Perfezionamento Sant'Anna (Italy)

Multi-Layer Optical Networks

Wen-De Zhong, Nanyang Technological University (Singapore)

Virtual Network

Yaohui Jin, Shanghai Jiao Tong University (China)

Energy Efficient Design

Pin-Han Ho, University of Waterloo (Canada)

Media Access Control

Dirk Breuer, Deutsche Telekom AG (Germany)

Physical Impairments in Optical Networks

Christine Tremblay, École de technologie supérieure, (Canada)

Fiber Access Networks

Bart Lannoo, Universiteit Gent (Belgium) 